British Journal of Education, Society \&
Behavioural Science
10(4): 1-10, 2015, Article no.BJESBS.19501
ISSN: 2278-0998
SCIENCEDOMAIN international
Www.Sciencedomain.org

\title{
Risk Factors for, and Effects of, Stress, Anxiety, and Depression in Adolescents
}

\author{
Gareth Richards $^{1^{*}}$ and Andrew P. Smith ${ }^{1}$ \\ ${ }^{1}$ Centre for Occupational \& Health Psychology, School of Psychology, Cardiff University, \\ United Kingdom.
}

Authors' contributions

This work was carried out in collaboration between both authors. Author GR carried out the statistical analysis and data interpretation, and drafted and revised the manuscript. Author APS designed and supervised the running of the project, and revised the manuscript for important intellectual content. Both authors read and approved the final manuscript prior to submission.

Article Information

DOI: 10.9734/BJESBS/2015/19501

Editor(s):

(1) Shao-I Chiu, Taipei College of Maritime Technology of Center for General Education,

Taiwan.

Reviewers:

(1) Anonymous, Universite de Rouen, France. (2) Anonymous, Vytautas Magnus University, Lithuania. Complete Peer review History: http://sciencedomain.org/review-history/10156

Original Research Article

Received $12^{\text {th }}$ June 2015

Accepted $3^{\text {rd }}$ July 2015

Published 14 ${ }^{\text {th }}$ July 2015

\section{ABSTRACT}

Aims: Stress, anxiety, and depression are alarmingly common in the general population, can be extremely debilitating, and are a huge cost to public health services. Understanding risk factors associated with such conditions may therefore be useful in helping devise intervention strategies. Though much research has been conducted in the adult population, relatively few studies have investigated these problems in adolescents from the UK. This is a gap in the literature that the current paper aims to address.

Study Design: The current research utilised a cross-sectional design.

Place and Duration of Study: Data were collected from three secondary schools in Cornwall, UK, in June 2013.

Methodology: Data from the Cornish Academies Project were used to investigate links between demographic and lifestyle variables and single item measures of stress, anxiety, and depression. The sample included 2307 secondary school children aged $11-17$ (48.5\% male, 51.5\% female) from the South West of England. 
Results: A number of risk factors were identified, including female gender, low sleep hours, and belonging to a higher school year. In addition to this, the effects of stress anxiety, and depression on school attendance, Key Stage 3/Key Stage 4 English and maths attainment, and the occurrence of behavioural sanctions were investigated. After demographic and lifestyle covariates had been controlled for, high stress was found to predict the occurrence of behavioural sanctions, and high depression was associated with below average English and maths attainment.

Conclusion: Though the findings presented are informative in themselves, the identification of correlates of mental health problems in this demographic group may also be of benefit to future studies that utilise multivariate approaches to data analysis.

Keywords: Adolescent behavior; anxiety; depression; stress.

\section{INTRODUCTION}

It has been estimated that approximately 450 million people worldwide have a mental health problem [1]. In the context of the UK, The Office for National Statistics [2] reported that $19 \%$ of those aged 16 and over attained a General Health Questionnaire score indicative of anxiety or depression. In addition to this, the UK Health and Safety Executive [3] stated that work-related stress, anxiety, and depression cost the UK economy in excess of $£ 530$ million per year.

Due to the complexity of relationships between stress, anxiety, and depression, it is considered important for research to take a multidimensional approach [4]. Not only does this allow for interactions between variables to be assessed, and for the influence of confounding factors to be controlled for statistically, it is also more likely to reflect real-world processes. In order to utilise such methods, it is therefore necessary to identify risk factors associated with poor mental health. A number of such variables have been identified in adult populations, such as female gender, low social class, low income and education, unemployment, not being married, and having a poor somatic health status [5-7]. Certain aspects of lifestyle have also been associated with mental health. For instance, aerobic exercise has been found to have antidepressant and anxiolytic effects in adults, and can protect against the harmful consequences of stress [8].

Considering the seriousness of the effects of stress, anxiety, and depression on society as a whole, it is surprising to find that few data have been published, which relate to such phenomena in British adolescents. A population-based sample of British children and adolescents aged 5-15 [9] did, however, identify the prevalence rate of DSM-IV disorders to be $9.5 \%$. Furthermore, a longitudinal assessment of prevalence rates from age 9 to 16 [10] determined that $36.7 \%$ of participants had at least one psychiatric disorder at some point during the study period.

As rates for psychiatric disorders have been shown to vary considerably across different cultures [6], the current paper aims to provide more recent estimates of the prevalence of stress, anxiety, and depression in British adolescents. Cross-sectional data are presented from the Cornish Academies Project, a largescale longitudinal programme of research. Demographic and lifestyle risk factors of poor mental health were identified, and the effects of mental health on school performance outcomes were examined.

\section{MATERIALS AND METHODS}

\subsection{Participants}

The Cornish Academies Project was a longitudinal research programme investigating dietary effects on school performance and mental health in secondary school children from the South West of England. Participants in the current study came from the second crosssection of data, which has been described in detail elsewhere [11]. At this time-point, the cohort consisted of 3323 pupils (2610 of whom had consented to take part), and 2307 completed the questionnaires. An age range of 11-17 $(\mathrm{M}=13.6, \mathrm{SD}=1.49)$ was observed, and the sex ratio was relatively balanced $(48.5 \%$ male, $51.5 \%$ female).

\subsection{Apparatus/Materials}

Single item measures from the Wellbeing Process Questionnaire [12] were administered, for which participants were asked to state how frequently they had experienced stress, anxiety, and depression over the previous six months, on 
a five-point scale $(1=$ not at all, $2=$ rarely, $3=$ sometimes, $4=$ frequently, $5=$ very frequently). Single items were used because they have been shown to be valid and reliable, can identify overall risk, and save time in comparison to full-length measures [13]. Three items were employed to measure the frequency of taking part in exercise; participants were asked to report how frequently they performed mildly energetic, moderately energetic, and vigorous exercise using a four-point scale ( 1 = three times a week or more, 2 = once or twice a week, $3=$ about once to three times a month, $4=$ never/hardly ever). These three items were factor analysed into a single-item solution, the details of which have been reported elsewhere [11]. In addition to this, participants were asked to state how many hours they typically spent asleep each night.

\subsection{Design and Procedure}

Pupils filled out the questionnaires after being administered them by teachers at their schools, and demographic and school performance data were acquired through the School Information Management System. This included age, sex, school year, school attendance, number of detentions/behavioural sanctions incurred, Key Stage 3/Key Stage 4 English and maths attainment, ethnicity, special educational needs status, eligibility/ineligibility to receive free school meals (used as an indication of socioeconomic status [14]), whether the child was cared for by a non-parental guardian, and whether English was spoken as an additional language. Statistical procedures were carried out using IBM SPSS version 20 .

\section{RESULTS}

The percentage of pupils who reported to have 'frequently' or 'very frequently' experienced stress, anxiety, and depression over the previous six months was alarmingly high at $26 \%, 14.6 \%$, and $13.2 \%$, respectively (for frequency data, see Table 1). Though it should be acknowledged that one study using single item measurements of these concepts might not be an accurate representation of their true prevalence rates, these findings suggest that a large proportion of mental health problems begin relatively early in life. This is therefore an important area to address, as early intervention may potentially be able to reduce negative effects in both adolescents and adults.

\subsection{Demographic and Lifestyle Risk Factors of Poor Mental Health}

Data for the single item measures of mental health were recoded into dichotomous variables, with those who answered with 1 or 2 ('not at all' or 'rarely' experienced stress, anxiety, or depression) being placed into the above average group, and those who answered with 3,4 , or 5 ('sometimes', 'frequently', or 'very frequently' experienced stress, anxiety or depression) comprising the below average group. Initial Chisquare tests were performed to investigate associations between these variables and certain aspects of demography and lifestyle. Ethnicity, whether or not English was spoken as an additional language, and whether or not participants were looked after by a non-parental guardian were not investigated because the numbers of participants in the minority groups were particularly small: non-White $\mathrm{N}=84(2.8 \%)$, English spoken as an additional language $\mathrm{N}=51$ $(1.7 \%)$, looked after by a non-parental guardian, $\mathrm{N}=17(.6 \%)$.

It was found that being female was associated with high stress, anxiety, and depression. Though no differences were observed in relation to the schools that the children came from, significant effects were observed regarding their year group. In each case, this reflected significant linear-by-linear trends in which mental health decreased in higher school years: stress, $\mathrm{X} 2(1, \mathrm{~N}=2193)=28.289, P<.001$; anxiety, $\mathrm{X} 2$ $(1, N=2183)=42.181, P<.001$; depression, $X 2$ $(1, N=2181)=5.593, P=.02$. Having a SEN status was also associated with high depression, though no effects were observed regarding stress or anxiety. Interestingly, high anxiety was associated with not being eligible to receive free school meals, though no such effects were observed for stress or depression. Sleeping for fewer than average hours per night and exercising infrequently were also associated with high stress, anxiety, and depression. For all Chisquare values and cross-tabulations between mental health and demographic variables, see Table 2; for mental health and lifestyle variables, see Table 3.

To further examine the nature of the effects observed in the univariate analysis, forwards logistic regression was used. The reason for doing this was so that associations between demographic and lifestyle variables and mental health could be examined independently. 
Table 1. Frequency information for single item measures of stress, anxiety, and depression

\begin{tabular}{llllll}
\hline & Not at all & Rarely & Sometimes & Frequently & Very frequently \\
\hline Stress & $216(9.6 \%)$ & $606(26.9 \%)$ & $\mathbf{8 4 2}(\mathbf{3 7 . 4} \%)$ & $393(17.5 \%)$ & $192(8.5 \%)$ \\
Anxiety & $430(19.2 \%)$ & $\mathbf{8 5 6 ( 3 8 . 2 \% )}$ & $625(27.9 \%)$ & $225(10 \%)$ & $103(4.6 \%)$ \\
Depression & $\mathbf{8 0 8 ( 3 6 . 1 \% )}$ & $653(29.2 \%)$ & $481(21.5 \%)$ & $187(8.4 \%)$ & $108(4.8 \%)$ \\
\hline \multicolumn{5}{c}{ Note: Modal values are displayed in bold }
\end{tabular}

The variables entered into the models were sex, school attended, school year, presence/absence of a special educational needs status, eligibility/ ineligibility to receive free school meals, sleep, and exercise frequency.

High stress remained associated with being female, OR $=1.944,95 \% \mathrm{Cl}[1.601,2.362]$, Wald $=44.878, P<.001$, sleeping for fewer hours than average per night, $\mathrm{OR}=1.33,95 \% \mathrm{Cl}[1.082$, 1.635], Wald $=7.352, P=.007$, and being in a higher school year, Wald $=20.863, P<.001$. More specifically, in regards to this latter finding, compared to Year 7, higher stress levels were reported in Year 9, OR $=1.472,95 \% \mathrm{Cl}[1.085$, 1.999], Wald $=6.158, P=.01$, Year 10, OR = $1.676,95 \% \mathrm{Cl}[1.211,2.321]$, Wald $=9.684$, $P=.002$, and Year 11, OR $=1.533,95 \% \mathrm{Cl}$ $[1.11,2.118]$, Wald $=6.712, P=.01$, but not in Year $8, \mathrm{OR}=.955,95 \% \mathrm{Cl}[.71,1.285]$, Wald $=$ $.092, P=.76$.

In a similar manner to the risk factors of stress, high anxiety remained associated with being female, $\mathrm{OR}=2.344,95 \% \mathrm{Cl}[1.932,2.845]$, Wald $=74.559, P<.001$, sleeping for fewer hours than average, $\mathrm{OR}=1.368,95 \% \mathrm{Cl}[1.117,1.677]$, Wald $=9.168, P=.002$, and being in a higher school year, Wald $=23.474, P<.001$. As with the effect of school year on stress, compared to Year 7, higher anxiety was reported in Year 9, $\mathrm{OR}=1.397,95 \% \mathrm{Cl}[1.024,1.906]$, Wald $=$ 4.463, $P=.04$, Year 10, OR $=1.709,95 \% \mathrm{Cl}$ $[1.238,2.359]$, Wald $=10.63, P=.001$, and Year $11, \mathrm{OR}=1.963,95 \% \mathrm{Cl}[1.422,2.711]$, Wald $=$ $16.798, P<.001$, but not in Year $8, \mathrm{OR}=1.122$, $95 \% \mathrm{Cl}[.821,1.535]$, Wald $=.522, P=.47$. Unlike stress, high anxiety also remained significantly associated with not being eligible to receive free school meals, OR $=.663,95 \% \mathrm{Cl}$ $[.483, .911]$, Wald $=6.443, P=.01$.

In a similar way to stress and anxiety, high depression remained associated with being female, OR $=1.934,95 \% \mathrm{Cl}[1.58,2.369]$, Wald $=40.744, P<.001$, and sleeping for fewer hours than average per night, $\mathrm{OR}=1.465,95 \% \mathrm{Cl}$ $[1.202,1.785]$, Wald $=14.33, P<.001$. In addition to this, having a special educational needs status, $\mathrm{OR}=1.302,95 \% \mathrm{Cl}[1.037$, 1.635], Wald $=5.156, P=.02$, and exercising infrequently, $\mathrm{OR}=1.343,95 \% \mathrm{Cl}[1.1,1.639]$, Wald $=8.411, P=.004$, also both remained associated with high instances of depression.

\subsection{Effects of Poor Mental Health on School Performance}

Associations between school performance and mental health were initially examined at the univariate level using Chi-square tests. Low school attendance was found to be associated with high stress, anxiety and depression. Interestingly, high anxiety was also associated with high English attainment, though this effect is likely to be a Type 1 error considering that high maths attainment was related to low stress, depression, and anxiety (though the latter effect was only marginally significant). High stress and high depression were also associated with increased instances of behavioural sanctions (the latter effect again being marginally significant). For all Chi-square values and crosstabulations between mental health variables and school performance, see Table 4.

In order to investigate the effects of mental health on school performance at the multivariate level, stress, anxiety, and depression (along with each of the demographic and lifestyle variables discussed in the previous section) were entered into forwards logistic regression models upon the dependent variables of school attendance, English attainment, maths attainment, and behavioural sanctions. Though no effects of mental health on school attendance remained significant, high stress was predictive of the occurrence of a high number of behavioural sanctions, $\mathrm{OR}=1.388,95 \% \mathrm{Cl}[1.07,1.799]$, Wald $=6.102, P=.01$. High depression was also found to predict both low English attainment, OR $=1.313,95 \% \mathrm{Cl}[1.059,1.629], \mathrm{Wald}=6.149, P$ $=.01$, and low maths attainment, OR $=1.287$, $95 \% \mathrm{Cl}[1.042,1.59]$, Wald $=5.481, P=.02$. The effect on English attainment was particularly interesting considering that no such finding had been made at the univariate level. 
Table 2. Chi-square values and cross-tabulations between demographic variables and mental health

\begin{tabular}{|c|c|c|c|c|c|c|c|c|c|c|c|c|c|c|c|c|}
\hline & & & \multicolumn{2}{|c|}{ Sex } & \multicolumn{3}{|c|}{ Academy } & \multicolumn{5}{|c|}{ School year } & \multicolumn{2}{|c|}{ SEN status } & \multicolumn{2}{|l|}{ FSM } \\
\hline & & & Male & Female & Academy 1 & Academy 2 & Academy 3 & Year 7 & Year 8 & Year 9 & Year 10 & Year 11 & Yes & No & Yes & No \\
\hline \multirow{9}{*}{ Stress } & Low & Count & 446 & 301 & 226 & 390 & 206 & 192 & 201 & 152 & 126 & 131 & 205 & 604 & 86 & 716 \\
\hline & & Expected count & 359.6 & 387.4 & 225.9 & 406.1 & 190.1 & 161.6 & 167.9 & 165.3 & 151.4 & 155.8 & 213.1 & 595.9 & 88.8 & 713.2 \\
\hline & & Row \% & $59.7 \%$ & $40.3 \%$ & $27.5 \%$ & $47.4 \%$ & $25.1 \%$ & $23.9 \%$ & $25.1 \%$ & $19 \%$ & $15.7 \%$ & $16.3 \%$ & $25.3 \%$ & $74.7 \%$ & $10.7 \%$ & $89.3 \%$ \\
\hline & & Adjusted residual & 7.9 & -7.9 & .0 & -1.4 & 1.7 & 3.4 & 3.6 & -1.5 & -2.9 & -2.8 & -.8 & .8 & -.4 & .4 \\
\hline & High & Count & 538 & 759 & 392 & 721 & 314 & 250 & 258 & 300 & 288 & 295 & 379 & 1029 & 157 & 1235 \\
\hline & & Expected count & 624.4 & 672.6 & 392.1 & 704.9 & 329.9 & 280.4 & 291.1 & 286.7 & 262.6 & 270.2 & 370.9 & 1037.1 & 154.2 & 1237.8 \\
\hline & & Row \% & $41.5 \%$ & $58.5 \%$ & $27.5 \%$ & $50.5 \%$ & $22 \%$ & $18 \%$ & $18.5 \%$ & $21.6 \%$ & $20.7 \%$ & $21.2 \%$ & $26.9 \%$ & $73.1 \%$ & $11.3 \%$ & $88.7 \%$ \\
\hline & & Adjusted residual & -7.9 & 7.9 & .0 & 1.4 & -1.7 & -3.4 & -3.6 & 1.5 & 2.9 & 2.8 & & -.8 & & -.4 \\
\hline & & $x^{2}$ & \multicolumn{2}{|c|}{$63.064, P<.001$} & \multicolumn{3}{|c|}{$3.109, P=.21$} & \multicolumn{5}{|c|}{$33.93, P<.001$} & \multicolumn{2}{|c|}{$.659, P=.42$} & \multicolumn{2}{|c|}{$.159, P=.69$} \\
\hline \multirow{9}{*}{ Anxiety } & Low & Count & 674 & 502 & 348 & 624 & 314 & 291 & 289 & 256 & 213 & 203 & 330 & 933 & 157 & 1095 \\
\hline & & Expected count & 565.2 & 610.8 & 352.7 & 634.7 & 298.7 & 252.3 & 260.4 & 258.7 & 236.9 & 243.7 & 330.8 & 932.2 & 138.7 & 1113.3 \\
\hline & & Row \% & $57.3 \%$ & $42.7 \%$ & $27.1 \%$ & $48.5 \%$ & $24.4 \%$ & $23.2 \%$ & $23.1 \%$ & $20.4 \%$ & $17 \%$ & $16.2 \%$ & $26.1 \%$ & $73.9 \%$ & $12.5 \%$ & $87.5 \%$ \\
\hline & & Adjusted residual & 9.8 & -9.8 & -.4 & -.9 & 1.6 & 4.2 & 3.1 & -.3 & -2.6 & -4.5 & -.1 & .1 & 2.5 & -2.5 \\
\hline & High & Count & 305 & 556 & 266 & 481 & 206 & 149 & 165 & 195 & 200 & 222 & 248 & 696 & 85 & 847 \\
\hline & & Expected count & 413.8 & 447.2 & 261.3 & 470.3 & 221.3 & 187.7 & 193.6 & 192.3 & 176.1 & 181.3 & 247.2 & 696.8 & 103.3 & 828.7 \\
\hline & & Row \% & $35.4 \%$ & $64.6 \%$ & $27.9 \%$ & $50.5 \%$ & $21.6 \%$ & $16 \%$ & $17.7 \%$ & $20.9 \%$ & $21.5 \%$ & $23.8 \%$ & $26.3 \%$ & $73.7 \%$ & $9.1 \%$ & $90.9 \%$ \\
\hline & & Adjusted residual & -9.8 & 9.8 & .4 & .9 & -1.6 & -4.2 & -3.1 & .3 & 2.6 & 4.5 & .1 & -.1 & -2.5 & 2.5 \\
\hline & & $x^{2}$ & \multicolumn{2}{|c|}{$95.408, P<.001$} & \multicolumn{3}{|c|}{$2.415, P=.3$} & \multicolumn{5}{|c|}{$42.931, P<.001$} & \multicolumn{2}{|c|}{$.006, P=.94$} & \multicolumn{2}{|c|}{$6.342, P=.01$} \\
\hline \multirow{9}{*}{ Depression } & Low & Count & 723 & 615 & 392 & 715 & 354 & 304 & 318 & 280 & 252 & 271 & 357 & 1081 & 152 & 1273 \\
\hline & & Expected count & 644.7 & 693.3 & 401 & 721.7 & 338.3 & 287.5 & 299.9 & 294.7 & 269.2 & 273.8 & 379.6 & 1058.4 & 157.4 & 1267.6 \\
\hline & & Row \% & $54 \%$ & $46 \%$ & $26.8 \%$ & $48.9 \%$ & $24.2 \%$ & $21.3 \%$ & $22.3 \%$ & $19.6 \%$ & $17.7 \%$ & $19 \%$ & $24.8 \%$ & $75.2 \%$ & $10.7 \%$ & $89.3 \%$ \\
\hline & & Adjusted residual & 7.3 & -7.3 & -.9 & -.6 & 1.7 & 1.9 & 2 & -1.6 & -2 & -.3 & -2.3 & 2.3 & -.8 & .8 \\
\hline & High & Count & 257 & 439 & 222 & 390 & 164 & 136 & 141 & 171 & 160 & 148 & 225 & 542 & 89 & 668 \\
\hline & & Expected count & 335.3 & 360.7 & 213 & 383.3 & 179.7 & 152.5 & 159.1 & 156.3 & 142.8 & 145.2 & 202.4 & 564.6 & 83.6 & 673.4 \\
\hline & & Row $\%$ & $36.9 \%$ & $63.1 \%$ & $28.6 \%$ & $50.3 \%$ & $21.1 \%$ & $18 \%$ & $18.7 \%$ & $22.6 \%$ & $21.2 \%$ & $19.6 \%$ & $29.3 \%$ & $70.7 \%$ & $11.8 \%$ & $88.2 \%$ \\
\hline & & Adjusted residual & -7.3 & 7.3 & .9 & .6 & -1.7 & -1.9 & -2 & 1.6 & 2 & .3 & 2.3 & -2.3 & .8 & -.8 \\
\hline & & $x^{2}$ & \multicolumn{2}{|c|}{$53.688, P<.001$} & \multicolumn{3}{|c|}{$2.86, P=.24$} & \multicolumn{5}{|c|}{$11.244, P=.02$} & \multicolumn{2}{|c|}{$5.234, P=.02$} & \multicolumn{2}{|c|}{$.598, P=.44$} \\
\hline
\end{tabular}

Note: 'SEN' refers to the presence/absence of a special educational needs status; 'FSM' refers to eligibility/ineligibility to receive free school meals 
Table 3. Chi-square values and cross-tabulations between lifestyle variables and mental health

\begin{tabular}{|c|c|c|c|c|c|c|}
\hline & & & \multicolumn{2}{|c|}{ Sleep hours } & \multicolumn{2}{|c|}{ Exercise frequency } \\
\hline & & & High & Low & High & Low \\
\hline \multirow{9}{*}{ Stress } & Low & Count & 446 & 348 & 384 & 390 \\
\hline & & Expected count & 390.2 & 403.8 & 350.4 & 423.6 \\
\hline & & Row \% & $56.2 \%$ & $43.8 \%$ & $49.6 \%$ & $50.4 \%$ \\
\hline & & Adjusted residual & 5 & -5 & 3 & -3 \\
\hline & High & Count & 617 & 752 & 582 & 778 \\
\hline & & Expected count & 672.8 & 696.2 & 615.6 & 744.4 \\
\hline & & Row \% & $45.1 \%$ & $54.9 \%$ & $42.8 \%$ & $57.2 \%$ \\
\hline & & Adjusted residual & & 5 & -3 & 3 \\
\hline & & $x^{2}$ & & $p<.001$ & & \\
\hline \multirow{9}{*}{ Anxiety } & Low & Count & 673 & 571 & 581 & 631 \\
\hline & & Expected count & 611.6 & 632.4 & 549 & 663 \\
\hline & & Row \% & $54.1 \%$ & $45.9 \%$ & $47.9 \%$ & $52.1 \%$ \\
\hline & & Adjusted residual & 5.4 & -5.4 & 2.8 & -2.8 \\
\hline & High & Count & 387 & 525 & 382 & 532 \\
\hline & & Expected count & 448.4 & 463.6 & 414 & 500 \\
\hline & & Row \% & $42.4 \%$ & $57.6 \%$ & $41.8 \%$ & $58.2 \%$ \\
\hline & & Adjusted residual & -5.4 & 5.4 & -2.8 & 2.8 \\
\hline & & $x^{2}$ & & $8<.001$ & & 05 \\
\hline \multirow{9}{*}{ Depression } & Low & Count & 753 & 656 & 674 & 707 \\
\hline & & Expected count & 695 & 714 & 627.1 & 753.9 \\
\hline & & Row \% & $53.4 \%$ & $46.6 \%$ & $48.8 \%$ & $51.2 \%$ \\
\hline & & Adjusted residual & 5.3 & -5.3 & 4.3 & -4.3 \\
\hline & High & Count & 309 & 435 & 290 & 452 \\
\hline & & Expected count & 367 & 377 & 336.9 & 405.1 \\
\hline & & Row \% & $41.5 \%$ & $58.5 \%$ & $39.1 \%$ & $60.9 \%$ \\
\hline & & Adjusted residual & -5.3 & 5.3 & -4.3 & 4.3 \\
\hline & & $x^{2}$ & \multicolumn{2}{|c|}{$27.631, p<.001$} & \multicolumn{2}{|c|}{$18.402, p<.001$} \\
\hline
\end{tabular}

\section{DISCUSSION}

The current study aimed to provide an indication of the levels of stress, anxiety, and depression present in secondary school children from the UK. The levels reported were worryingly high, though considering that the sample was relatively homogenous, may not be generalisable to other adolescents from the UK or other countries. In addition to this, a number of covariates of poor stress and mental health were identified, and associations between mental health and school performance were examined.

\subsection{Covariates of Mental Health}

Female gender was predictive of high stress, anxiety, and depression, even after controlling for other demographic and lifestyle covariates, a finding that broadly reflects those made in older populations $[15,16]$. Of particular concern was the observation that mental health decreased in higher school years.
Although the effect regarding depression did not retain statistical significance after controlling for covariates, those relating to stress and anxiety did. These results are comparable to those of Ford et al. [9], who found the overall prevalence of DSM-IV disorders to increase with age throughout adolescence, though may be different from those observed in older populations. For instance, a study of Turkish university students [17], found that first and second years reported higher levels of stress, anxiety, and depression compared to third, fourth, and fifth years. Differences in findings such as these therefore highlight the importance of taking demographic variance into account when investigating mental health.

High stress, anxiety, and depression were all associated with low sleep hours. This potentially mirrors observations that insomniacs are more likely to report anxiety and depression [18], and to perceive their lives as being more stressful compared to good sleepers [19]. 
Richards and Smith; BJESBS, 10(4): 1-10, 2015; Article no.BJESBS. 19501

Table 4. Chi-square values and cross-tabulations between school performance and mental health

\begin{tabular}{|c|c|c|c|c|c|c|c|c|c|c|}
\hline & & & \multicolumn{2}{|c|}{ School attendance } & \multicolumn{2}{|c|}{ KS3/KS4 English } & \multicolumn{2}{|c|}{ KS3/KS4 Maths } & \multicolumn{2}{|c|}{ Behavioral sanctions } \\
\hline & & & High & Low & High & Low & High & Low & High & Low \\
\hline \multirow{9}{*}{ Stress } & Low & Count & 456 & 346 & 382 & 414 & 409 & 386 & 152 & 654 \\
\hline & & Expected count & 433.9 & 368.1 & 394 & 402 & 382 & 413 & 170.8 & 635.2 \\
\hline & & Row \% & $56.9 \%$ & $43.1 \%$ & $48 \%$ & $52 \%$ & $51.4 \%$ & $48.6 \%$ & $18.9 \%$ & $81.1 \%$ \\
\hline & & Adjusted residual & 2 & -2 & -1.1 & 1.1 & 2.4 & -2.4 & -2 & 2 \\
\hline & High & Count & 732 & 662 & 696 & 686 & 636 & 744 & 314 & 1079 \\
\hline & & Expected count & 754.1 & 639.9 & 684 & 698 & 663 & 717 & 295.2 & 1097.8 \\
\hline & & Row \% & $52.5 \%$ & $47.5 \%$ & $50.4 \%$ & $49.6 \%$ & $46.1 \%$ & $53.9 \%$ & $22.5 \%$ & $77.5 \%$ \\
\hline & & Adjusted residual & -2 & 2 & 1.1 & -1.1 & -2.4 & 2.4 & 2 & -2 \\
\hline & & $x^{2}$ & \multicolumn{2}{|c|}{$3.874, p=.049$} & \multicolumn{2}{|c|}{$1.137, p=.29$} & \multicolumn{2}{|c|}{$5.805, p=.02$} & \multicolumn{2}{|c|}{$4.146, p=.04$} \\
\hline \multirow{9}{*}{ Anxiety } & Low & Count & 706 & 546 & 595 & 648 & 618 & 624 & 251 & 1005 \\
\hline & & Expected count & 677.5 & 574.5 & 618.1 & 624.9 & 596.6 & 645.4 & 265.1 & 990.9 \\
\hline & & Row \% & $56.4 \%$ & $43.6 \%$ & $47.9 \%$ & $52.1 \%$ & $49.8 \%$ & $50.2 \%$ & $20 \%$ & $80 \%$ \\
\hline & & Adjusted residual & 2.5 & -2.5 & -2 & 2 & 1.9 & -1.9 & -1.5 & 1.5 \\
\hline & High & Count & 477 & 457 & 483 & 442 & 422 & 501 & 211 & 722 \\
\hline & & Expected count & 505.5 & 428.5 & 459.9 & 465.1 & 443.4 & 479.6 & 196.9 & 736.1 \\
\hline & & Row \% & $51.1 \%$ & $48.9 \%$ & $52.2 \%$ & $47.8 \%$ & $45.7 \%$ & $54.3 \%$ & $22.6 \%$ & $77.4 \%$ \\
\hline & & Adjusted residual & -2.5 & 2.5 & 2 & -2 & -1.9 & 1.9 & 1.5 & -1.5 \\
\hline & & $x^{2}$ & \multicolumn{2}{|c|}{$6.095, p=.01$} & \multicolumn{2}{|c|}{$4.011, p=.045$} & \multicolumn{2}{|c|}{$3.459, p=.063$} & \multicolumn{2}{|c|}{$2.226, p=.14$} \\
\hline \multirow{9}{*}{ Depression } & Low & Count & 800 & 625 & 720 & 697 & 718 & 694 & 282 & 1146 \\
\hline & & Expected count & 769.9 & 655.1 & 702 & 715 & 678.3 & 733.7 & 299.7 & 1128.3 \\
\hline & & Row \% & $56.1 \%$ & $43.9 \%$ & $50.8 \%$ & $49.2 \%$ & $50.8 \%$ & $49.2 \%$ & $19.7 \%$ & $80.3 \%$ \\
\hline & & Adjusted residual & 2.7 & -2.7 & 1.6 & -1.6 & 3.6 & -3.6 & -2 & 2 \\
\hline & High & Count & 380 & 379 & 353 & 396 & 321 & 430 & 177 & 582 \\
\hline & & Expected count & 410.1 & 348.9 & 371 & 378 & 360.7 & 390.3 & 159.3 & 599.7 \\
\hline & & Row \% & $50.1 \%$ & $49.9 \%$ & $47.1 \%$ & $52.9 \%$ & $42.7 \%$ & $57.3 \%$ & $23.3 \%$ & $76.7 \%$ \\
\hline & & Adjusted residual & -2.7 & 2.7 & -1.6 & 1.6 & -3.6 & 3.6 & 2 & -2 \\
\hline & & $x^{2}$ & \multicolumn{2}{|c|}{$7.357, p=.007$} & \multicolumn{2}{|c|}{$2.658, p=.1$} & \multicolumn{2}{|c|}{$12.908, p<.001$} & \multicolumn{2}{|c|}{$3.814, p=.051$} \\
\hline
\end{tabular}


Though it is difficult to infer the direction of the relationships observed (and they could indeed be bi-directional), these findings suggest that adolescents who sleep for relatively few hours per night may represent a group at increased risk of experiencing mental health problems.

High anxiety was associated with not being eligible to receive free school meals, and the effect remained significant after controlling for additional covariates. This finding is somewhat counterintuitive in that eligibility to receive free school meals is a proxy indication of low socioeconomic status [14], and financial difficulties have been shown to increase depression in British university students [20].

Having a special educational needs status remained associated with high depression, even after additional covariates had been controlled for. Infrequent exercise was also associated with high instances of depression, a finding that may mirror the observation that exercise can have antidepressant effects in adults [8].

\subsection{Mental Health and School Performance}

Though high stress, anxiety, and depression were all initially associated with low school attendance, none of these effects remained significant once demographic and lifestyle covariates had been controlled for. However, high depression was associated with low English and maths attainment, the former effect having not been detected at the univariate level. Differences between univariate and multivariate findings such as these may highlight the need to control for demographic and lifestyle covariates when investigating the effects of mental health on school performance outcomes. These results are also similar to the finding that depression can predict decreases in exam performance in university students [20]. Furthermore, high stress was found to remain predictive of accruing a high number of behavioural sanctions, an effect similar to the observation that a high number of stressful life events is associated with increased delinquency in adolescents [21].

\subsection{Limitations}

Though the current study benefitted from a large sample size, the population studied was somewhat homogenous (consisting mainly of White children from an area of relatively low socioeconomic background). In addition to this, the study is limited in that the data used were only cross-sectional in nature. Though demographic and lifestyle factors were conceptualised as being risk factors of mental health, whereas school performance measures were conceptualised as being outcomes, the potential for reverse-causation and bidirectionality cannot be overlooked. For instance, though being depressed might negatively impact school attainment, achieving poor grades may also be a cause of depression.

\section{CONCLUSION}

The current study aimed to provide a profile of the levels of stress, anxiety, and depression present in a cohort of British secondary school children. In addition to this, a number of demographic and lifestyle risk factors of poor mental health were identified, which broadly reflect similar findings reported in older populations. Of particular concern are the findings that high stress, anxiety, and depression were relatively common, that the occurrence of poor mental health increased throughout secondary school education, and that it also appeared to negatively affect certain aspects of school performance. These findings therefore suggest strongly that mental health in adolescence should be an area of particular importance for future research.

\section{CONSENT}

Written informed consent was acquired from each participant prior to data collection.

\section{ETHICAL APPROVAL}

Ethical clearance was granted by Cardiff University's School of Psychology Ethics Committee (ethical clearance number: EC.12.09.11.3187).

\section{ACKNOWLEDGEMENTS}

The current research was supported by a grant from The Waterloo Foundation (grant number: 503692). Every person who contributed significantly to the current work has been acknowledged, and neither of the authors have any conflicts of interest to declare. The funders had no involvement in designing of the study, data collection, analysis and interpretation of data, or writing of the manuscript. 


\section{COMPETING INTERESTS}

Authors have declared that no competing interests exist.

\section{REFERENCES}

1. World Health Organization. Mental disorders affect one in four people. 2001; 10:4. Accessed 12 June 2015.

Available:http://www.who.int/whr/2001/med ia centre/press release/en/

2. Office for National Statistics. Measuring national well-being - Health. 2013;6:19. Accessed 12 June 2015.

Available:http://www.ons.gov.uk/ons/dcp17 1766 310300.pdf

3. Health and Safety Executive. Workplace stress costs Great Britain in excess of $£ 530$ million. 2007;11:7. Accessed 12 June 2015.

Available:http://www.hse.gov.uk/press/200 7/c07021.htm

4. Galvin J, Smith AP. Stress in U.K. mental health training: A multi-dimensional comparison study. Br J Educ Soc Behav Sci. 2015;9(3):161-175.

DOI:10.9734/BJESBS/2015/18519\#sthash .nkcCAdEt.dpuf

5. Jacobi $F$, Wittchen $\mathrm{H}-\mathrm{U}$, Hölting $\mathrm{C}$, Höfler $M$, Pfister $H$, Müller $N$, et al. Prevalence, co-morbidity and correlates of mental disorders in the general population: Results from the German health interview and examination survey (GHS). Psychol Med. 1999;34(4):597-611.

DOI: $10.1017 / \mathrm{s} 0033291703001399$

6. Andrade L, Caraveo-Anduaga JJ, Berglund P, Bijl R, Kessler RC, Demler O, et al. Cross-national comparisons of the prevalence and correlates of mental disorders. Bull World Health Organ. 2000; 78(4):413-426.

7. Eisenberg D, Gollust SE, Golberstein E, Hefner JL. Prevalence and correlates of depression, anxiety, and suicidality among university students. Am J Orthopsychiatry. 2007;77(4):534-542.

DOI: $10.1037 / 0002-9432.77 .4 .534$

8. Salmon P. Effects of physical exercise on anxiety, depression, and sensitivity to stress: A unifying theory. Clin Psychol Rev. 2001;21(1):33-61.

DOI: $10.1016 / s 0272-7358(99) 00032-x$

9. Ford T, Goodman R, Meltzer H. The British Child and Adolescent Mental Health Survey 1999: The prevalence of DSM-IV disorders. J Am Acad Child Adolesc Psychiatry. 2003;42(10):1203-1211. DOI:10.1097/00004583-200310000-00011

10. Costello EJ, Mustillo S, Erkanli A, Keeler G, Angold A. Prevalence and development of psychiatric disorders in childhood and adolescence. JAMA Psychiatry. 2003; 60(8):837-844.

DOI: 10.1001/archpsyc.60.8.837

11. Richards G, Malthouse A, Smith AP. The diet and behaviour scale (DABS): Testing a new measure of food and drink consumption in a cohort of secondary school children from the south west of England. J Food Res. 2015;4(3):148-161. DOI: 10.5539/jfr.v4n3p148

12. Williams G. Researching and developing mental health and well-being assessment tools for supporting employers and employees in Wales [dissertation]. Cardiff University; 2014.

13. Williams G, Smith AP. A holistic approach to stress and well-being. Part 6: The Wellbeing Process Questionnaire (WPQ Short Form). Occup Health Work. 2012; 9(1):29-31.

14. Shuttleworth I. The relationship between social deprivation, as measured by individual free school meal eligibility, and educational attainment at GCSE in Northern Ireland: A preliminary investigation. Br Educ Res J. 1995;21(4): 487-504.

DOI: $10.1080 / 0141192950210404$

15. Mahmoud JSR, Staten R, Hall LA, Lennie TA. The relationship among young adult college students' depression, anxiety, stress, demographics, life satisfaction, and coping styles. Issues Ment Health Nurs. 2012;33(3):149-156.

DOI: 10.3109/01612840.2011.632708

16. Newbury-Birch D, Kamali F. Psychological stress, anxiety, depression, job satisfaction, and personality characteristics in preregistration house officers. Postgrad Med J. 2001;77(904):109-111.

DOI: $10.1136 / p m j .77 .904 .109$

17. Bayram N, Bilgel N. The prevalence and socio-demographic correlations of depression, anxiety and stress among a group of university students. Soc Psychiatry Psychiatr Epidemiol. 2008; 43(8):667-672.

DOI: $10.1007 / \mathrm{s} 00127-008-0345-\mathrm{x}$ 
18. Taylor DJ, Lichstein $\mathrm{KL}$, Durrence $\mathrm{HH}$, Reidel BW, Bush AJ. Epidemiology of insomnia, depression, and anxiety. Sleep. 2005;28(11):1457-1464.

19. Morin CM, Rodrigue $S$, Ivers $H$. Role of stress, arousal, and coping skills in primary insomnia. Psychosom Med. 2003;65(2): 259-267.

DOI:10.1097/01.psy.0000030391.09558.a 3
20. Andrews B, Wilding JM. The relation of depression and anxiety to life-stress and achievement in students. $\mathrm{Br} \mathrm{J}$ Psychol. 2004;95(4):509-521.

DOI: $10.1348 / 0007126042369802$.

21. Hoffmann JP, Cerbone FG. Stressful life events and delinquency escalation in early adolescence. Criminology. 1999;37(2): 343-374.

DOI: 10.1111/j.1745-9125.1999.tb00489.x

(c) 2015 Richards and Smith; This is an Open Access article distributed under the terms of the Creative Commons Attribution License (http://creativecommons.org/licenses/by/4.0), which permits unrestricted use, distribution, and reproduction in any medium, provided the original work is properly cited.

Peer-review history:

The peer review history for this paper can be accessed here: http://sciencedomain.org/review-history/10156 